Journal of Advanced Research in Fluid Mechanics and Thermal Sciences

\title{
Effect of Thermal Collector Height and Radius on Hydrodynamic Flow Control in Small Solar Chimney
}

\author{
Ahmed Daimallah ${ }^{1,}$, Mohamed Lebbi $^{2}$, Mohand Said Lounici $^{1}$, Lyes Boutina $^{2}$ \\ 1 LEMI, FT, Université M'hamed Bougara de Boumerdes, Avenue de l'indépendance 35000, Boumerdes, Algeria \\ 2 Unité de Recherche Appliquée en Energies Renouvelables, URAER, Centre de Développement des Energies Renouvelables, CDER, 47133, \\ Ghardaïa, Algeria
}

\section{ARTICLE INFO}

\section{Article history:}

Received 8 July 2019

Received in revised form 25 February 2020

Accepted 27 February 2020

Available online 27 May 2020

\section{Keywords:}

Small-scale solar chimney; Collector geometrical parameters; Numerical simulation; Thermo-hydrodynamic flow control; Turbulent natural convection

\section{ABSTRACT}

Solar chimney power plant (SCPP) is one of the promising technologies for solar energy utilization. It is an interesting system especially in large isolated desert areas due to its basic techniques and low operating costs. In this study, we investigate numerically the collector geometrical parameters effect on the hydrodynamic flow control in a solar chimney. The finite volume method and the SIMPLE algorithm have been used to solve the turbulent flow equations and energy equation. A standard $\mathrm{K}-\varepsilon$ model is used. The influence of the collector height $(0.05 \mathrm{~m} \leq \mathrm{Hc} \leq 0.5 \mathrm{~m})$ and the collector radius $(2.5 \mathrm{~m} \leq \mathrm{R} c \leq 15 \mathrm{~m})$ on the flow behavior has been numerically analyzed. The obtained results indicate that increasing the collector height and collector radius affect considerably the flow behavior and the SCPP performance. The mass flow rate is enhanced by about $27 \%$, for $\mathrm{Rc}=12.5 \mathrm{~m}$ and $\mathrm{Hc}=0.25 \mathrm{~m}$.

Copyright @ 2020 PENERBIT AKADEMIA BARU - All rights reserved

\section{Introduction}

Solar chimney power plant (SCPP) is an economic dispositive for production of electric Energy. In a SCPP, the air is heated by solar radiation captured in the collector. This leads to create the air acceleration in the tower chimney by buoyancy forces effect. These quantities of heated air pass throw aero-generator to produce electricity. Over the years, intensive research has been conducted on the solar chimney. Haaf et al., [1] investigated theoretical studies on Manzanares prototype. They discussed the energy balance, design criteria and the cost of the system and energy production analysis. Bernardes et al., [2] carried out a theoretical SCPP analysis based on a steady state laminar

\footnotetext{
* Corresponding author.

E-mail address: a.daimallah@univ-boumerdes.dz (Ahmed Daimallah)
} 
natural convection model. They used the finite volumes method in the generalized coordinates to solve the mathematical model. Von Backström and Gannon [3] interested in the solar chimney turbine characteristics, and found that a peak turbine total-to-total efficiency of around $90 \%$ was attainable. Maia et al., [4] carried out a theoretical and numerical study of the effect of geometric parameters on the performance of solar chimney. Chergui et al., [5] studied numerically the thermohydrodynamic behavior of the airflow through a solar chimney with well-defined appropriate boundary conditions. Larbi et al., [6] investigated the performance of an SCPP expected to provide electric power to the isolated villages located in Algerian southwestern. Sangi et al., [7] conducted a study based on Navier-Stokes, continuity and energy equations to develop a mathematical model of the SCPP. In addition, they used commercial software Fluent to simulate Manzanares SCPP. Their mathematical model and numerical analysis are in good agreement with experimental data. Lebbi et al., [8-9] analyzed numerically the effects of meteorological and geometrical parameters on the thermo-hydrodynamic flow control in the solar chimney. They found that the tower chimney dimensions affect significantly the flow behavior in such systems. Sudprasert et al., [10] carried out a numerical study to know the air humidity influence on the performance of SCPP. They obtained in the case of moist air the overall air temperature is higher than that in the case of dry air. Morteza Bayreh [11] conducted a 3D numerical investigation to perform the pressure drop effects of across turbine and the solar radiance on the performance of a SCPP, which is expected to provide electric power to a city located in the southern region of Iran. Their results indicate that the pressure drop and the solar radiation affect the efficiency. Besides, they obtained that the SCPP can provide up to 40-200 kW of power, depending on the season. Zhou et al., [12] examined the chimney height effect for SCPP. They found that the maximum height for convection and the optimal height for maximum power output increases with larger collector radius. Hamdan [13] developed a thermal mathematical model which related the power generation by SCPP to the geometry and size of the chimney and collector. Lee et al., [14] conducted an experimental study and identified the optimal configuration of solar chimney. They applied an organic Rankine cycle to generate electricity and found that the maximum outlet air temperature is approximately $125^{\circ} \mathrm{C}$. Bouabidi et al., [15] studied numerically and experimentally the effect of divergent collector on the performance of solar chimney. Their results indicate that the collector divergence affects the air flow behavior inside the chimney. Kinan et al., [16] investigated experimentally the performance of solar updraft power plant. They analyzed the effect of square and circular collector on the flow behavior. They found that circular collector gives higher velocity output than the square collector. Nasraoui et al., [17] proposed a novel collector design with double-pass counter flow mode. They carried out a comparison between three models; conventional collector, double-pass collector with parallel flow and double-pass collector with counter flow. The obtained results indicate that the double-passes counter flow collector increases the collector efficiency by $28 \%$ comparing to the conventional collector. Elwekeel et al., [18] examined the effect of different roughness shapes (smooth, triangular, square and curved grooves) of the collector roof on the SCPP performance. They obtained that the collector with triangular grooves gives the optimal performance. Ayadi et al., [19] analyzed the influence of the collector roof angle on the performance of the solar chimney power plant. Their results indicate that the negative collector roof angle increases the SCPP performance, specially the static pressure of the fluid decreases at the collector exit. Jing-yin Li [20] interested in the effects of collector radius and chimney height on the performance of solar chimney power plant with turbines. They found a limitation on the maximum collector radius, beyond which the attainable power output of the SCPP increases very slowly. Ayadi et al., [21] studied numerically, the effect of the collector roof height on the performance of the SCPP system. The results show that a small collector height presents additional generated power. Recently, Kebabsa et al., [22] studied numerically thermo-hydrodynamic behavior 
of an innovative solar chimney, named sloped collector entrance SCPP. They found that the new collector entrance design improves considerably the SCPP performance.

Obviously, the collector is an essential element in a solar chimney power plant. The optimization of its dimensions is necessary for SCPP performance improvement. The purpose of the present study is to investigate numerically the collector geometrical parameters effect (height and radius) on the turbulent flow behavior and performance of small-scale solar chimney.

\section{Description of the Geometry}

Figure 1 shows the physical model geometry of the proposed small-scale solar chimney. This design has a collector radius (Rc), collector height entrance $(\mathrm{Hc})$, tower chimney height $(\mathrm{Ht})$ and tower chimney radius $(\mathrm{Rt})$.

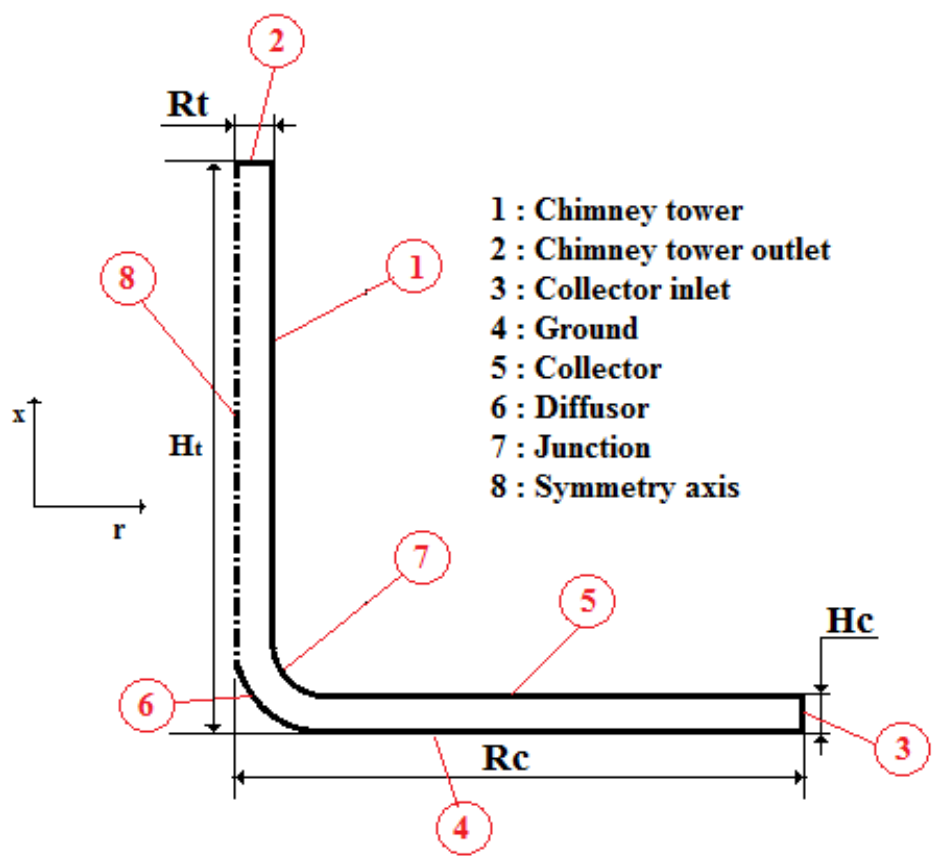

Fig. 1. Physical model of the problem

Table 1 summarizes the various geometrical dimensions considered in this study.

Table 1

Geometrical dimensions

\begin{tabular}{lllll}
\hline & $\mathrm{Rt}(\mathrm{m})$ & $\mathrm{Ht}(\mathrm{m})$ & $\mathrm{Hc}(\mathrm{m})$ & $\mathrm{Rc}(\mathrm{m})$ \\
\hline Case 1 & 0.25 & 5 & $0,05-0,075-0,83-0,1-0,2-$ & 5 \\
& & & $0,25-0,3-0,4$ and 0,5 & \\
Case 2 & 0.25 & 5 & 0.25 & $2,5-4-5-7,5-9-10-12,5$ and 15 \\
\hline
\end{tabular}

\section{Governing Equations}

The airflow through the solar chimney power plant is prescribed by two-dimensional turbulent natural convection in cylindrical coordinates. The fluid is incompressible and satisfies the Boussinesq approximation, which implies that the density variation with temperature is negligible except in the motion equation for the buoyancy term. The governing equations that describe the flow are given by 
Continuity equation

$\frac{\partial(\rho u)}{\partial x}+\frac{1}{r} \frac{\partial(r \rho v)}{\partial r}=0$

Momentum equations

$$
\begin{aligned}
\frac{\partial(\rho u u)}{\partial x}+\frac{1}{r} \frac{\partial(r \rho u v)}{\partial r}=-\frac{\partial}{\partial x}( & \left.p+\frac{2}{3} \rho k\right)+\frac{\partial}{\partial x}\left(\mu_{e} \frac{\partial u}{\partial x}\right)+ \\
& \frac{1}{r} \frac{\partial}{\partial r}\left(r \mu_{e} \frac{\partial u}{\partial r}\right)+\frac{\partial}{\partial x}\left(\mu_{e} \frac{\partial u}{\partial x}\right)+ \\
& \frac{1}{r} \frac{\partial}{\partial r}\left(r \mu_{e} \frac{\partial v}{\partial r}\right)+\left(\rho_{0}-\rho\right) g
\end{aligned}
$$

$$
\begin{aligned}
\frac{\partial(\rho u v)}{\partial x}+\frac{1}{r} \frac{\partial(r \rho v v)}{\partial r}=-\frac{\partial y}{\partial r}( & \left.p+\frac{2}{3} \rho k\right)+\frac{\partial}{\partial x}\left(\mu_{e} \frac{\partial v}{\partial x}\right)+ \\
& \frac{1}{r} \frac{\partial}{\partial r}\left(r \mu_{e} \frac{\partial v}{\partial r}\right)+\frac{\partial}{\partial x}\left(\mu_{e} \frac{\partial u}{\partial r}\right)+ \\
& \frac{1}{r} \frac{\partial}{\partial r}\left(r \mu_{e} \frac{\partial v}{\partial r}\right)-2 \mu_{e} \frac{1}{r^{2}}
\end{aligned}
$$

Energy equation

$$
\begin{aligned}
\frac{\partial(\rho u T)}{\partial x}+\frac{1}{r} \frac{\partial(r \rho v T)}{\partial r}=-\frac{\partial}{\partial x}[ & \left.\left(\frac{\mu}{p r}+\frac{\mu_{t}}{p r_{t}}\right) \frac{\partial T}{\partial x}\right]+ \\
& \frac{1}{r} \frac{\partial}{\partial r}\left[r\left(\frac{\mu}{p r}+\frac{\mu_{t}}{p r_{t}}\right) \frac{\partial T}{\partial r}\right]+\frac{\beta T}{C_{p}}\left(\frac{\partial \rho}{\partial t}+\frac{\partial(\rho u)}{\partial x}+\right. \\
& \left.\frac{1}{r} \frac{\partial(r \rho v)}{\partial r}-\rho \frac{\partial u}{\partial x}-\frac{\rho}{r} \frac{\partial(r v)}{\partial r}\right)
\end{aligned}
$$

Turbulent kinetic energy equation

$$
\frac{\partial(\rho u k)}{\partial x}+\frac{1}{r} \frac{\partial(r \rho v k)}{\partial r}=\frac{\partial}{\partial x}\left(\frac{\mu_{e}}{\sigma_{k}} \frac{\partial k}{\partial x}\right)+\frac{1}{r} \frac{\partial}{\partial r}\left(r \frac{\mu_{e}}{\sigma_{k}} \frac{\partial k}{\partial r}\right)+P_{k}+G_{k}-\rho c_{d} \varepsilon
$$

Dissipation of kinetic energy equation

$$
\frac{\partial(\rho u \varepsilon)}{\partial x}+\frac{1}{r} \frac{\partial(r \rho v \varepsilon)}{\partial r}=\frac{\partial}{\partial x}\left(\frac{\mu_{e}}{\sigma_{\varepsilon}} \frac{\partial \varepsilon}{\partial x}\right)+\frac{1}{r} \frac{\partial}{\partial r}\left(r \frac{\mu_{e}}{\sigma_{\varepsilon}} \frac{\partial k}{\partial r}\right)+\frac{C_{1} \varepsilon}{k}\left(P_{k}+G_{k}\right)\left(1+0.8 R_{f}\right)-C_{2} \rho \frac{\varepsilon^{2}}{k}
$$




\section{Boundary conditions}

We consider no-slip and impermeable boundary conditions at the solar chimney walls. Air enters in the cover at steady ambient temperature. The boundary conditions used for the velocity and for the temperature are:

$$
\begin{aligned}
& \text { At } \mathrm{x}=0,0 \leq \mathrm{r} \leq \mathrm{R}_{\mathrm{c}}: \mathrm{u}=\mathrm{v}=0, \mathrm{~T}=\mathrm{T}_{\text {ground }}, \frac{\partial k}{\partial x}=\frac{\partial \varepsilon}{\partial x}=0 \\
& \text { At } \mathrm{x}=\mathrm{Hc}, 0 \leq \mathrm{r} \leq \mathrm{Rc}: \mathrm{u}=\mathrm{v}=0, \mathrm{~T}=\mathrm{T}_{\text {conv }}, \frac{\partial k}{\partial x}=\frac{\partial \varepsilon}{\partial x}=0 \\
& \text { At } \mathrm{r}=\mathrm{R}_{\mathrm{t}}, \mathrm{H}_{\mathrm{c}} \leq \mathrm{x} \leq \mathrm{H}_{\mathrm{t}}: \mathrm{u}=\mathrm{v}=0, q=-k \frac{\delta T}{\delta r}=0, \frac{\partial k}{\partial r}=\frac{\partial \varepsilon}{\partial r}=0 \\
& \text { At } \mathrm{r}=0,0 \leq \mathrm{x} \leq \mathrm{H}_{\mathrm{t}}: \frac{\partial u}{\partial r}=\frac{\partial v}{\partial r}=0, \frac{\delta T}{\delta r}=0, \frac{\partial k}{\partial r}=\frac{\partial \varepsilon}{\partial r}=0 \\
& \text { At } \mathrm{r}=\mathrm{R}_{\mathrm{c}}, 0 \leq \mathrm{x} \leq \mathrm{H}_{\mathrm{c}}: \mathrm{u}=\mathrm{u}_{0}, \mathrm{v}=0, \mathrm{~T}=\mathrm{T}_{0}, k=\frac{3 I^{2} u^{2}}{2}, \varepsilon=\frac{k^{2}}{0.3 D_{h}} \\
& \text { At } \mathrm{x}=\mathrm{H}_{\mathrm{t}}, 0 \leq \mathrm{r} \leq \mathrm{R}_{\mathrm{t}}: \mathrm{u}=\mathrm{u}_{0}, \mathrm{v}=0, \mathrm{~T}=\mathrm{T}_{0}, k=\frac{3 I^{2} u^{2}}{2}, \varepsilon=\frac{k^{2}}{0.3 D_{h}}
\end{aligned}
$$

\section{Numerical Computation}

\subsection{Numerical Procedure}

The finite volume method and the SIMPLE algorithm have been used to solve the flow governing Eq. (1)-(6). The second order upwind scheme is used for convective terms discretization. The iterative solution is converged when the residuals across all nodes are less than $10^{-5}$.

\subsection{Mesh Generation}

A structured non-uniform grid with a more significant concentration on the inlet-outlet and junction regions was used. We adopt a $(64 \times 800)$ cells throughout the calculation domain since it has shown a negligible variation with a more refined grid (see Figure 2). 


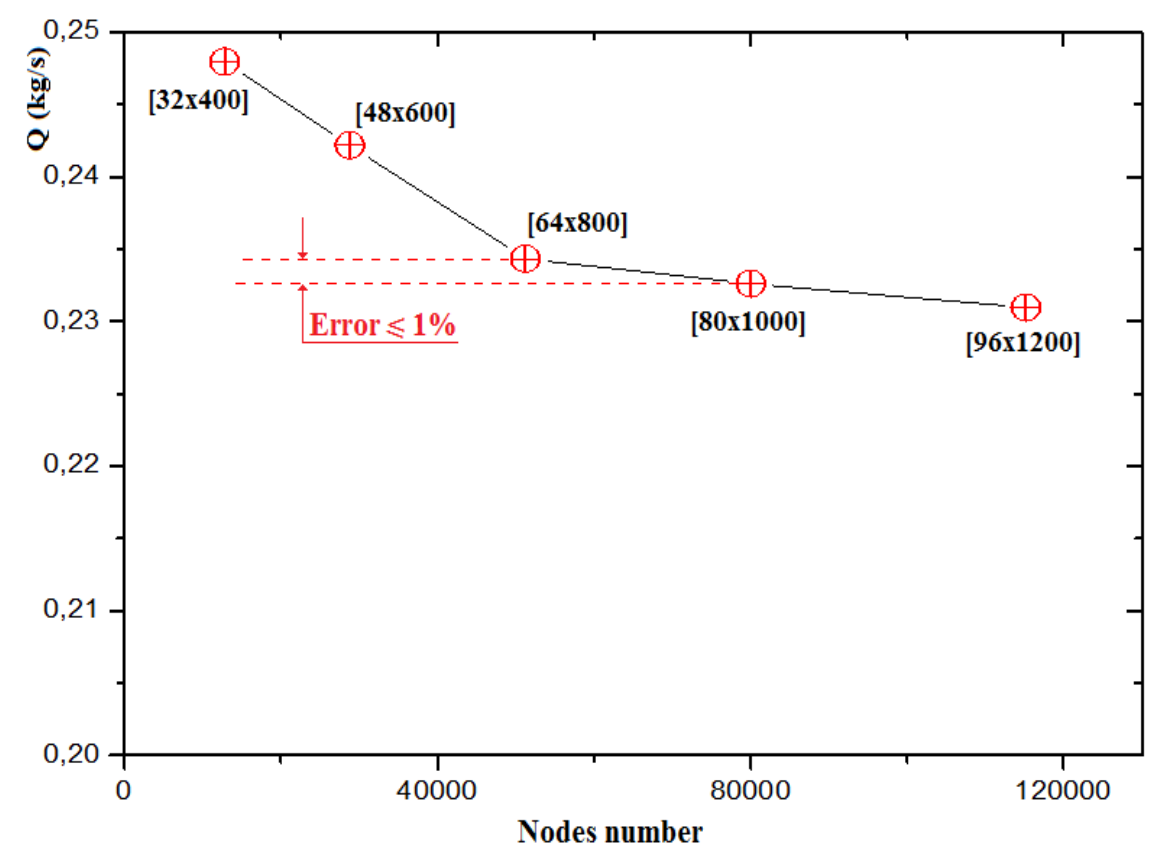

Fig. 2. Mesh independance study

\subsection{Validation}

In the aim to validate the numerical code, we carry out the calculation for SCPP under the same experimental conditions of Maia et al., [4]. Figure 3 shows velocity profiles in the tower cross-section, for the non-dimensional radius for $(r / R t=0.15)$. These obtained results indicate a good agreement with the theoretical and experimental value reported by Maia et al., [4] for the same geometrical conditions. The relative deviation between our results and those of Maia et al., [4] is around 9.7\%.

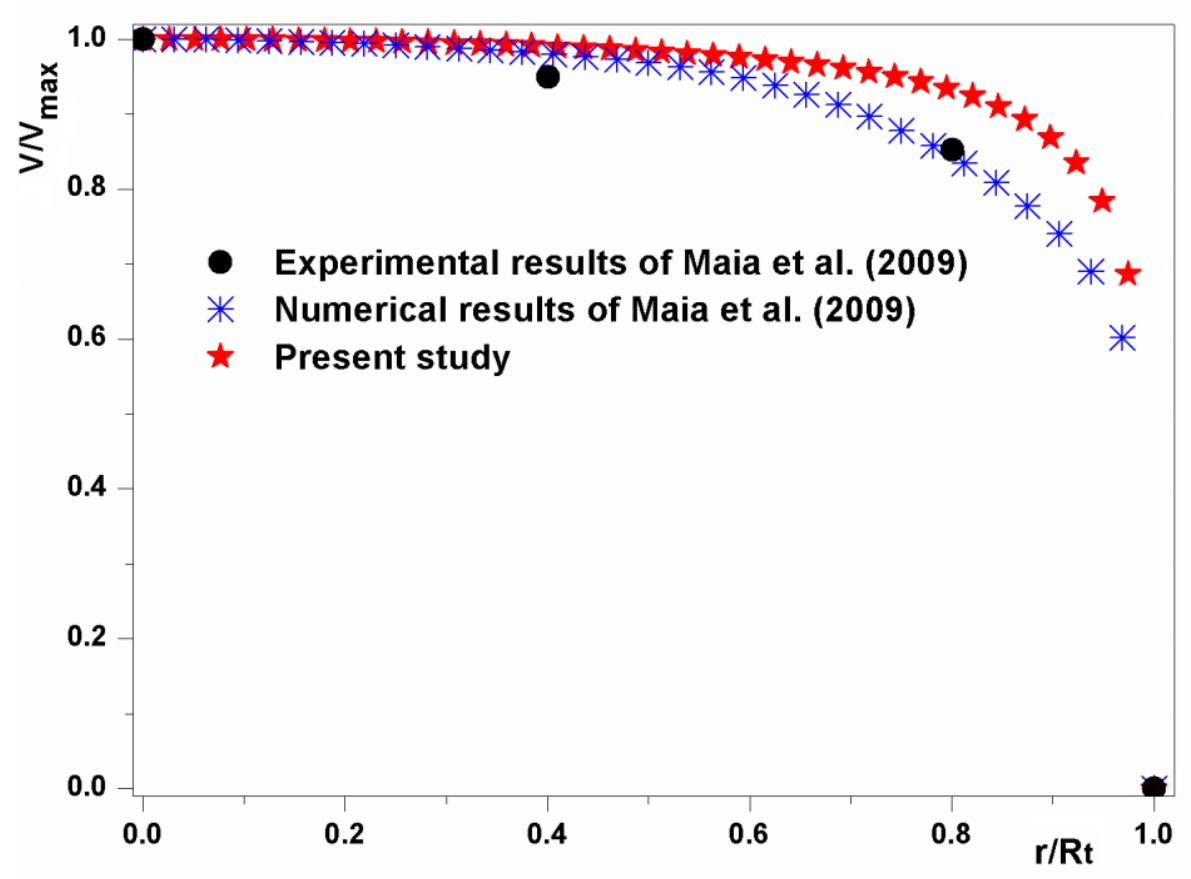

Fig. 3. Dimensionless velocity profile in the tower cross-section 


\section{Results and Discussion}

\subsection{Collector Height Effect on The Flow Structure}

\subsubsection{Collector height effect on the velocity field}

The velocity contours development for various collector heights are shown in Figure 4(a)-(c). We note that the distribution of the velocity field decreases in the collector when the collector height increases. In addition, we obtain a maximum velocity in the tower because of the heated air particles that move by the floatability buoyancy forces effect. The maximum of the velocity is reached at the entrance of the tower for small value of $(\mathrm{Hc}=0.05 \mathrm{~m})$. When it increases $(\mathrm{Hc}=0.5 \mathrm{~m})$, we note that the maximum velocity is localized at the tower exit.

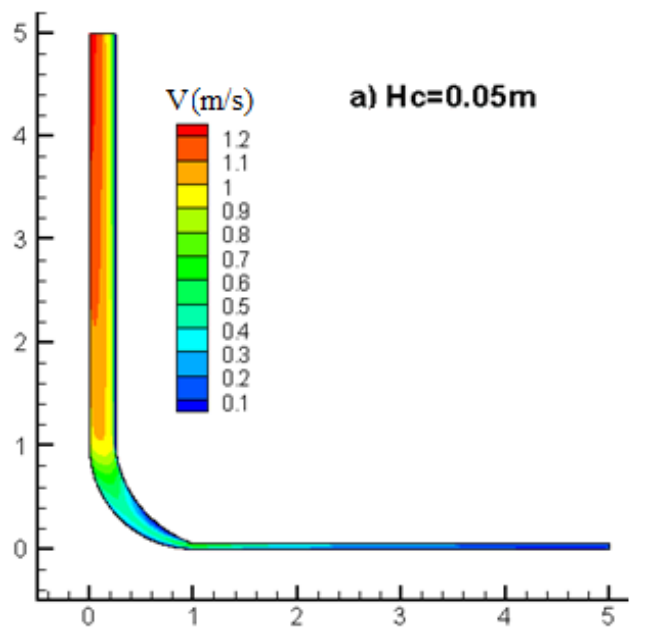

(a)

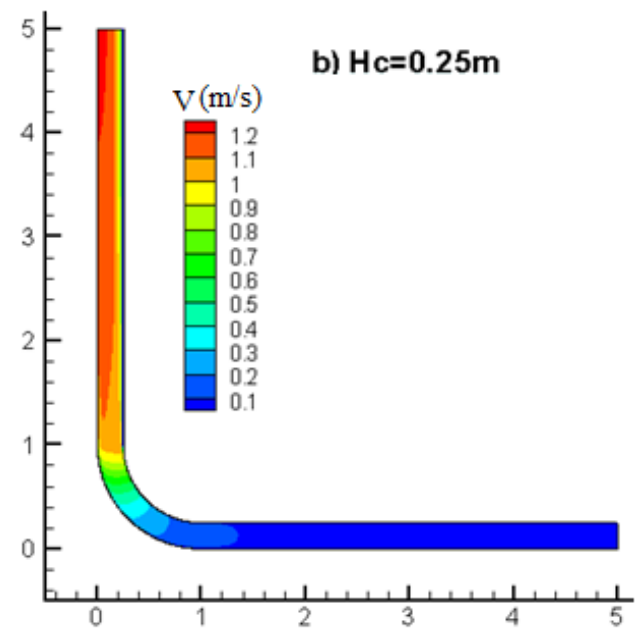

(b)

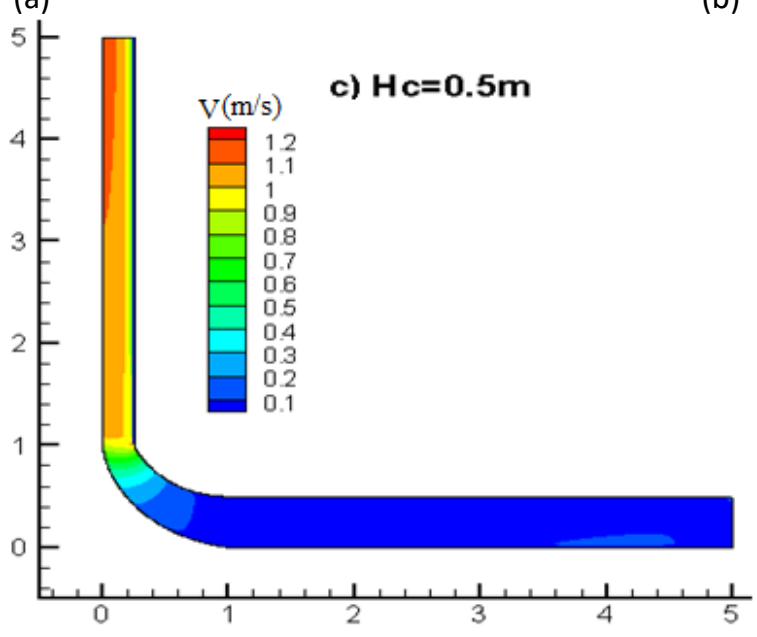

(c)

Fig. 4. (a)-(c) Velocity contours development in the solar chimney for various collector heights

The velocity evolution along the collector for various collector height values at $x=0.025 \mathrm{~m}$, is shown on Figure 5. The obtained results indicate that when we decrease the collector height, the velocity increases at the junction where it becomes maximal at the exit of the collector because of thermal exchange between the ground and airflow. 


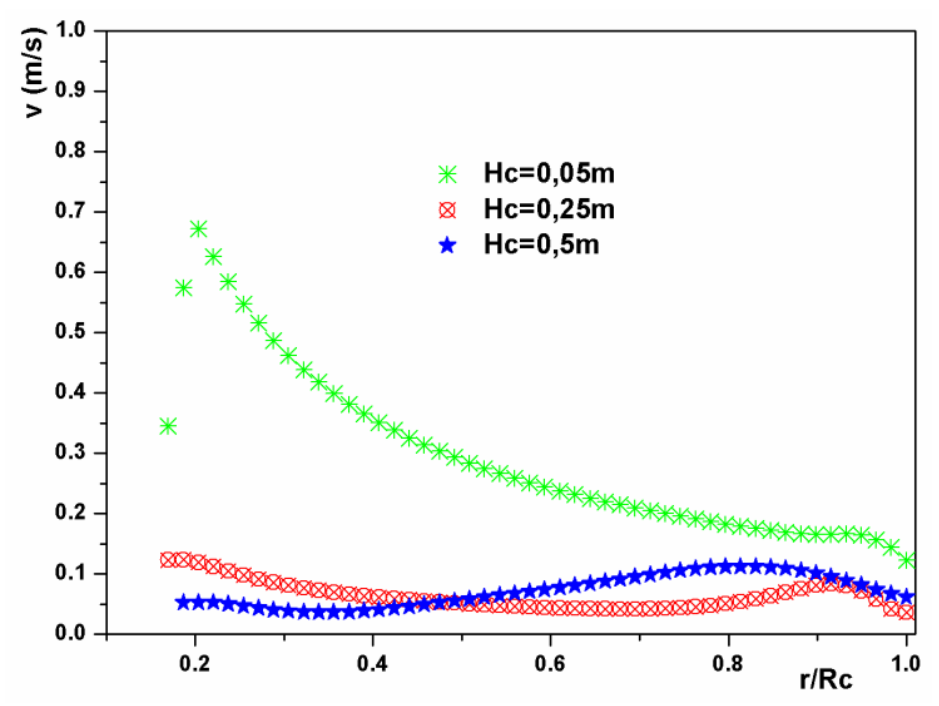

Fig. 5. Variation of velocity along the collector for various collector heights $(x=0.025 \mathrm{~m})$

\subsubsection{Collector height effect on stream line contours}

Figure 6(a)-(c) illustrates the streamline contours development for various collector heights. We note the appearance of the recirculation zone at the entrance of the collector. The size of this zone increases as function of the collector height, which can be justified by the decrease of mass flow rate.

\subsubsection{Collector height effect on the temperature contours}

The isothermal contours for various collector heights are shown in Figure 7(a)-(c). We observe that the isothermal lines distributions are structured and the temperature distribution decreases from the ground to the collector and increases from the entrance of the collector to the exit of the collector. We explain this by thermal exchange phenomena in natural convection between air and the ground in the collector. Besides, the increasing of collector height causes decreasing of temperature in both the collector and the tower by the flow acceleration effect.

Figure 8 shows the temperature evolution in the collector at $x=0.025 \mathrm{~m}$, for various collector heights. The results show that the temperature evolution along the collector becomes maximal at the entrance of the tower because of the increasing of the mass flow rate at the tower entrance.

\subsubsection{Collector height effect on mass flow rate}

Figure 9 displays the mass flow rate evolution versus collector height for a fixed collector radius $(R c=5 \mathrm{~m})$. The mass flow rate, first, increases. Then, it deceases after reaching a maximum value for $\mathrm{Hc}=0.10 \mathrm{~m}$. Those results show that for a fixed value of collector radius, there is a corresponding optimum value for collector height. 


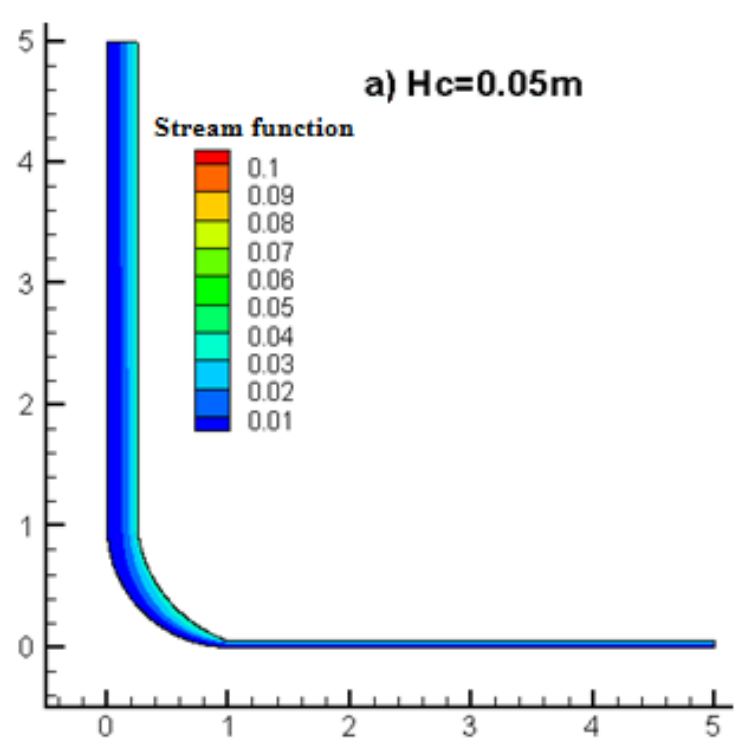

(a)

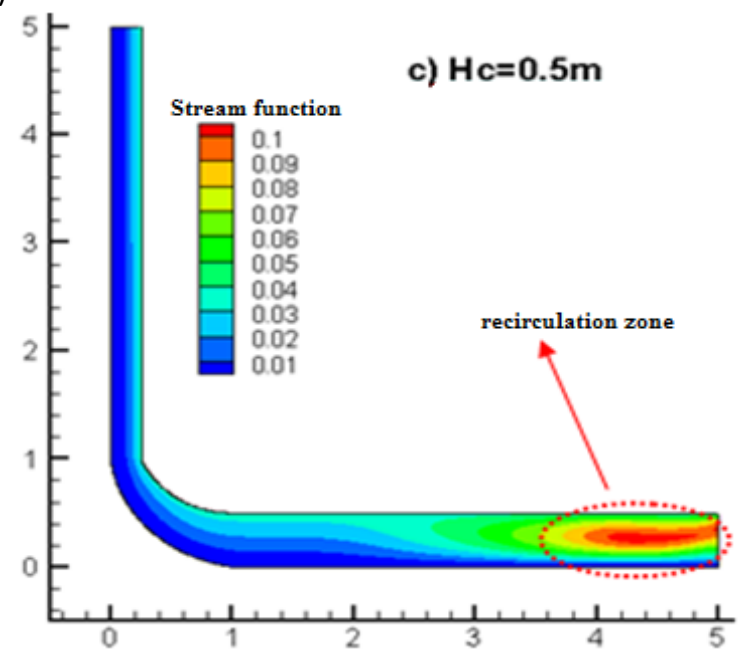

(c)

c) $\mathrm{Hc}=0.5 \mathrm{~m}$

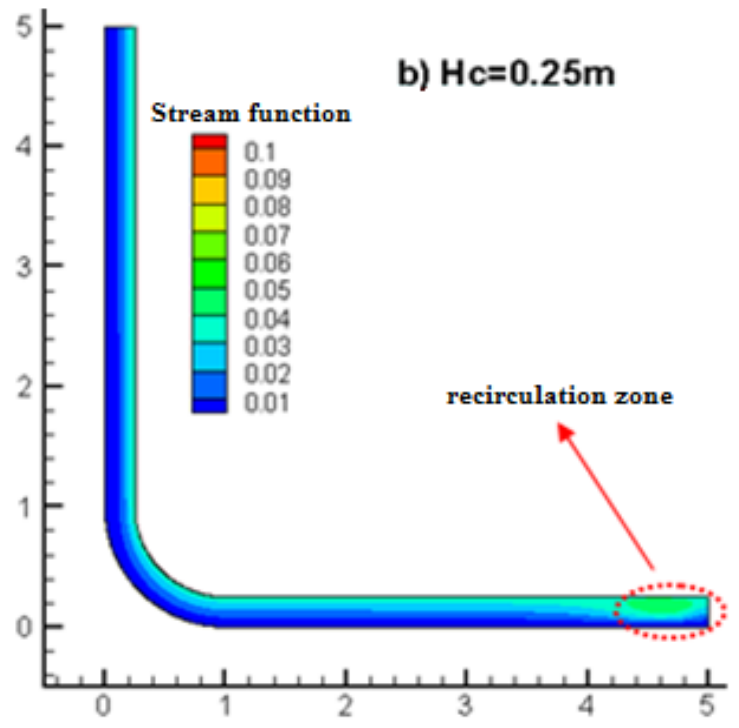

(b)

Fig. 6. (a)-(c) Streamlines distribution in the solar chimney for various collector heights

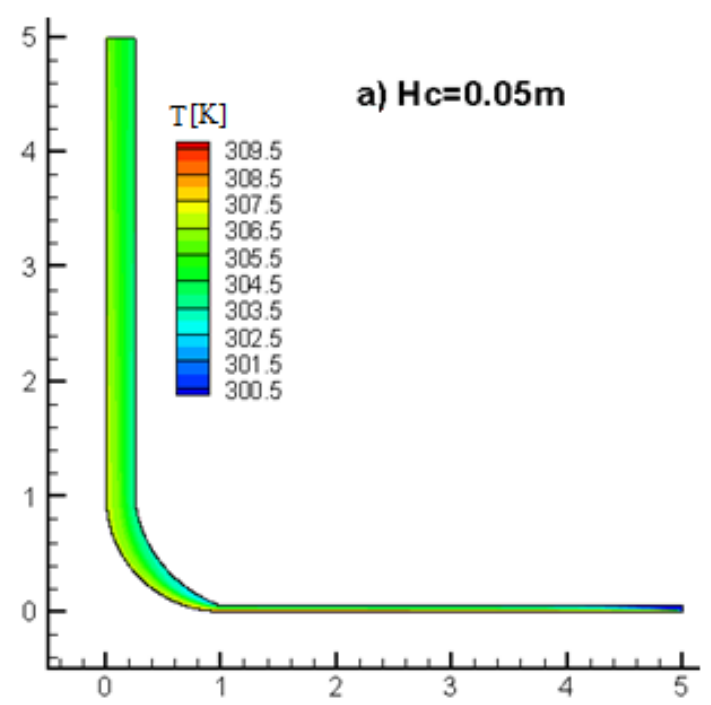

(a)

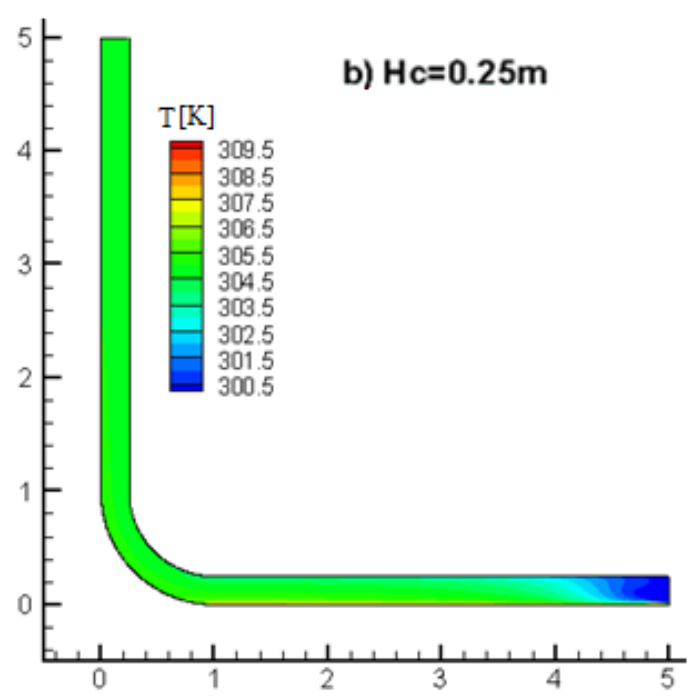

(b) 


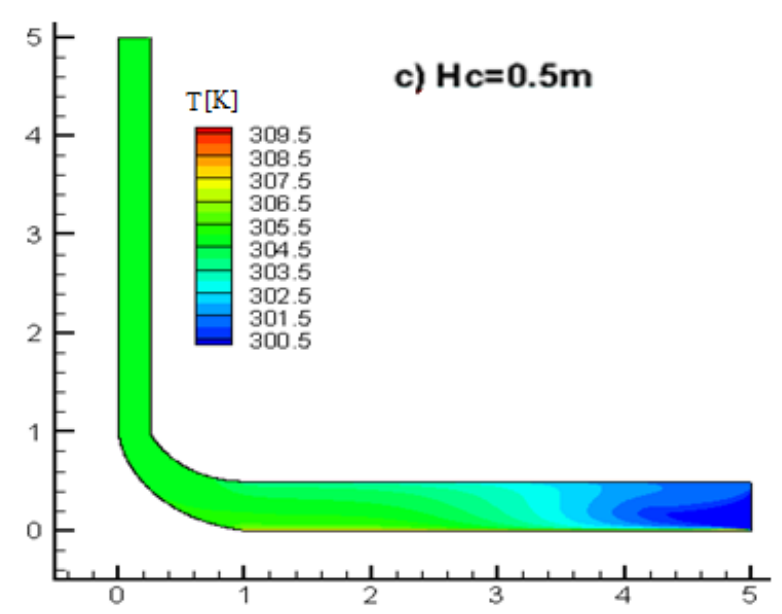

(c)

Fig. 7. (a)-(c) Isothermal contours evolution in the solar chimney for various collector heights

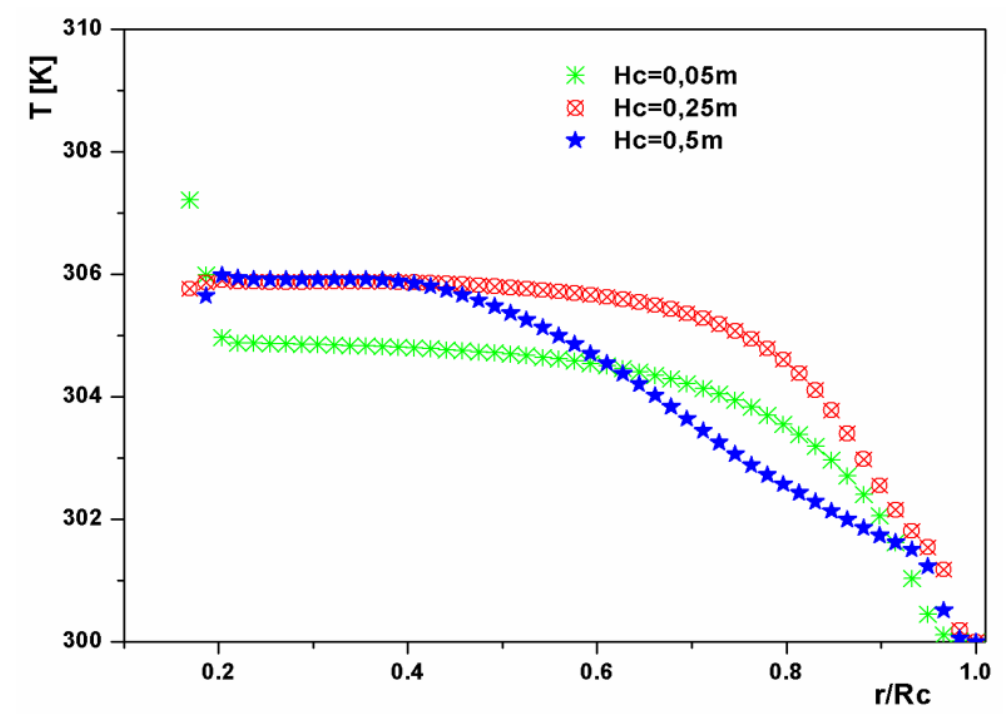

Fig. 8. Variation of temperature along the collector for various collector heights $(x=0.025 \mathrm{~m})$

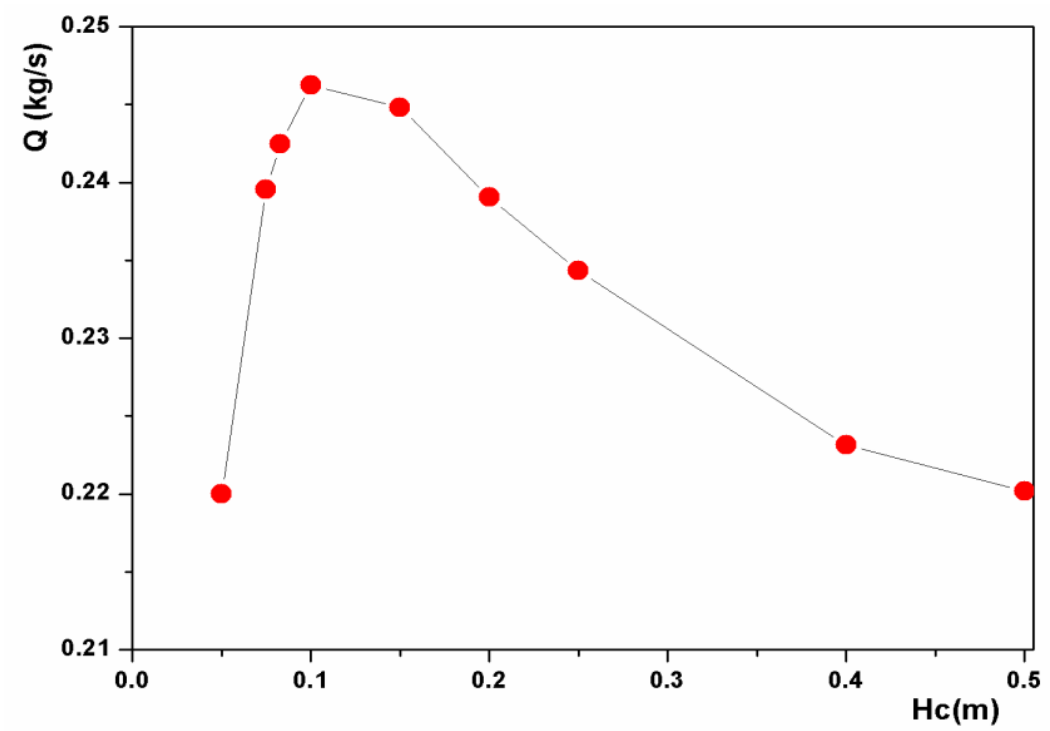

Fig. 9. Variation of Mass flow rate at the tower outlet versus the collector height 


\subsection{Collector Radius Effect on The Flow Structure}

\subsubsection{Collector radius effect on velocity}

Figure 10(a)-(c) plots velocity contours for different collector radius. The velocity field distribution evolves uniformly along the collector and it increases at the junction to achieve the maximum value at the axis because of the heated air particles that move by buoyancy forces effect.

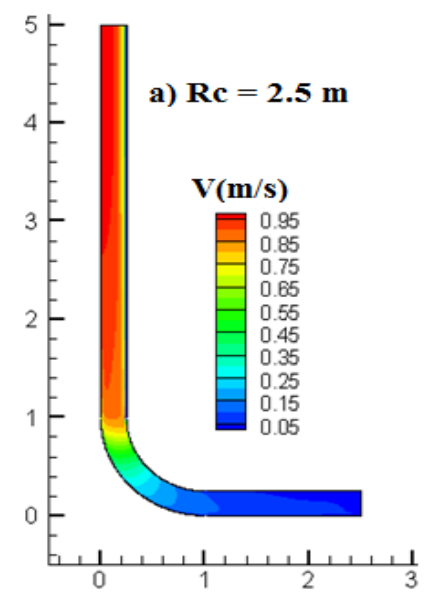

(a)

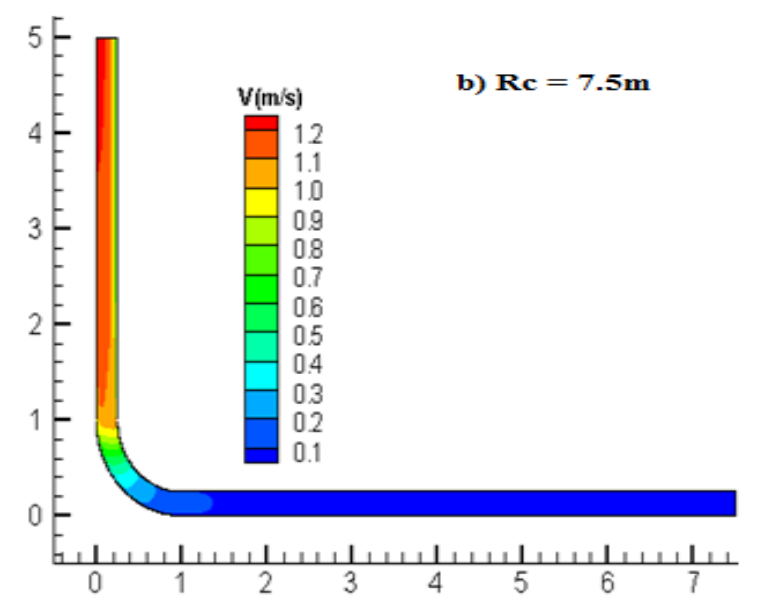

(b)

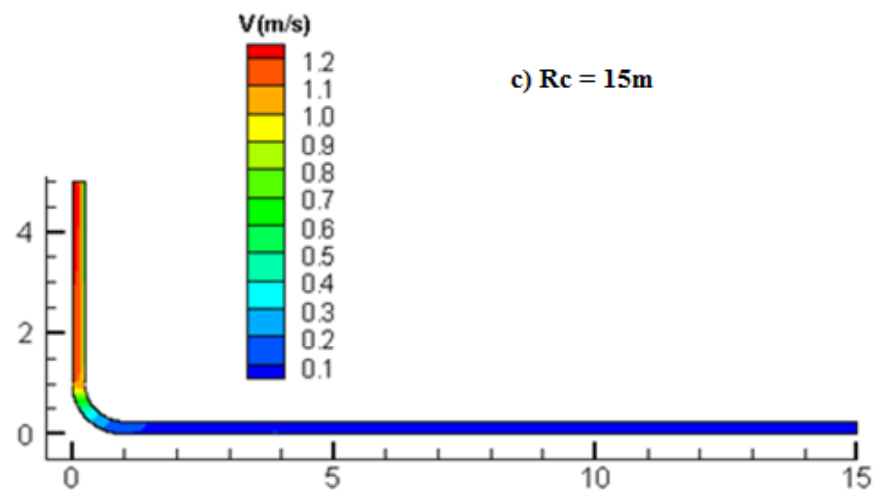

(c)

Fig. 10. (a)-(c) Velocity contours development in the solar chimney for different collector radius

The velocity evolution in a cross section of the collector $(r=0.25 \mathrm{~m})$, for different collector radius value is shown in Figure 11. We note that the air velocity increases proportionally versus the collector radius. 


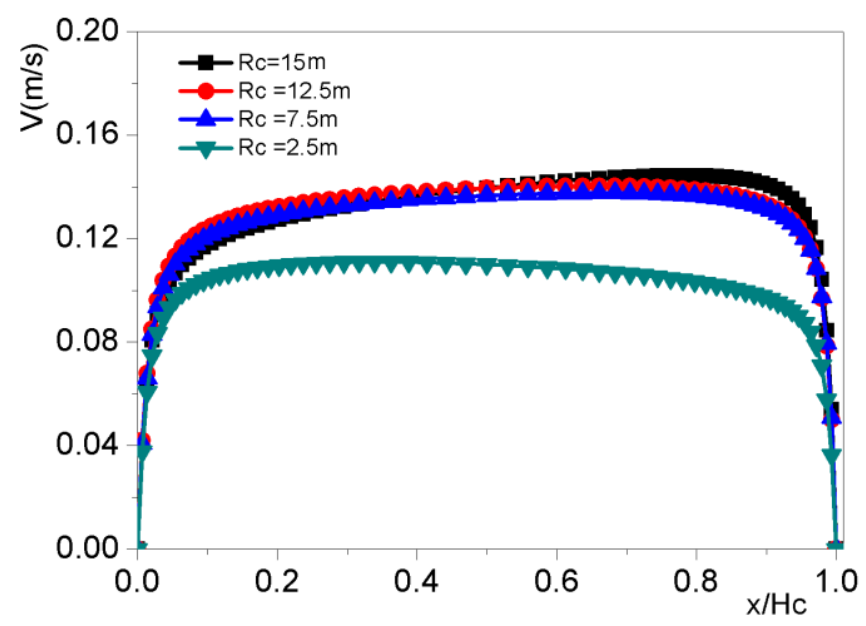

Fig. 11. Velocity profile variation in a cross section of the collector $(r=0.25 \mathrm{~m})$, for different collector radius

\subsubsection{Collector radius effect on the streamline distribution}

Figure 12(a)-(c) presents the Stream line development for different collector radius. We note that the recirculation zone size increases versus the collector radius. Also (for $R c=15 \mathrm{~m}$ ), we observe the development of recirculation zones at collector inlet. This result can be justified by the buoyancy effect due to temperature gradient dominate.

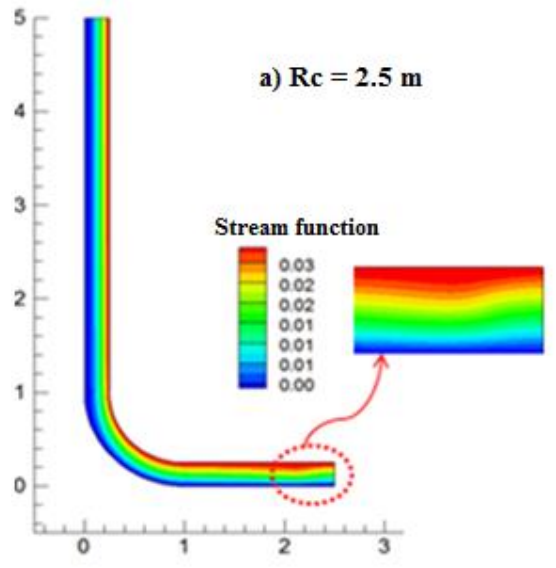

(a)

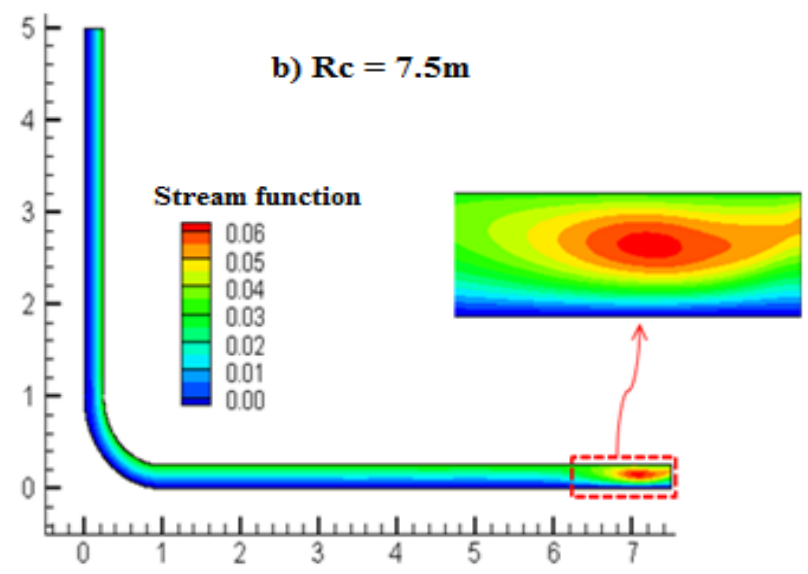

(b)

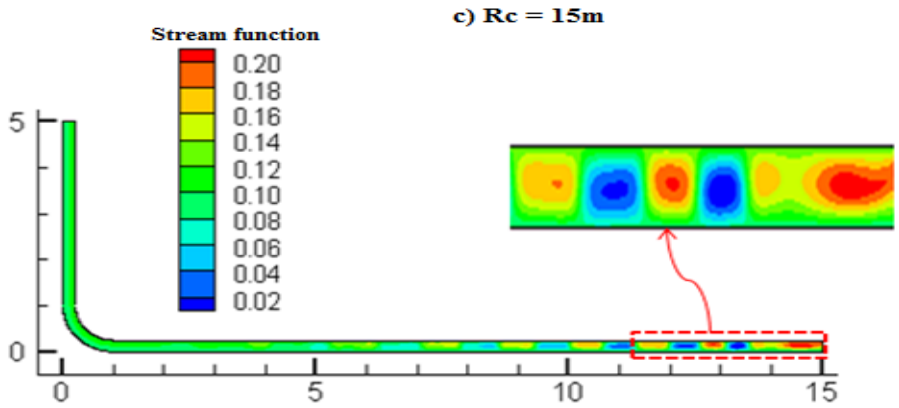

(c)

Fig. 12. (a)-(c) Streamlines distribution in the solar chimney for different collector radius 


\subsubsection{Collector radius effect on the temperature field}

The isothermal contours evolution for different collector radius is shown on Figure 13(a)-(c). For $\mathrm{Rc}=2.5 \mathrm{~m}$ and $\mathrm{Rc}=7.5 \mathrm{~m}$ (see Figure 13(a)-(b)), we note the development of structured isothermal contours in the collector level. For $\mathrm{Rc}=15 \mathrm{~m}$ (see Figure 13(c)), we observe the appearance of small cells created by buoyancy force effect at the collector entrance. This phenomenon is similar to Rayleigh-Benard problem.

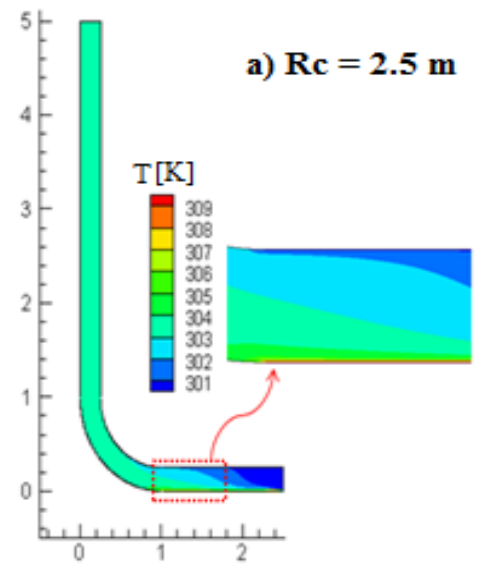

(a)

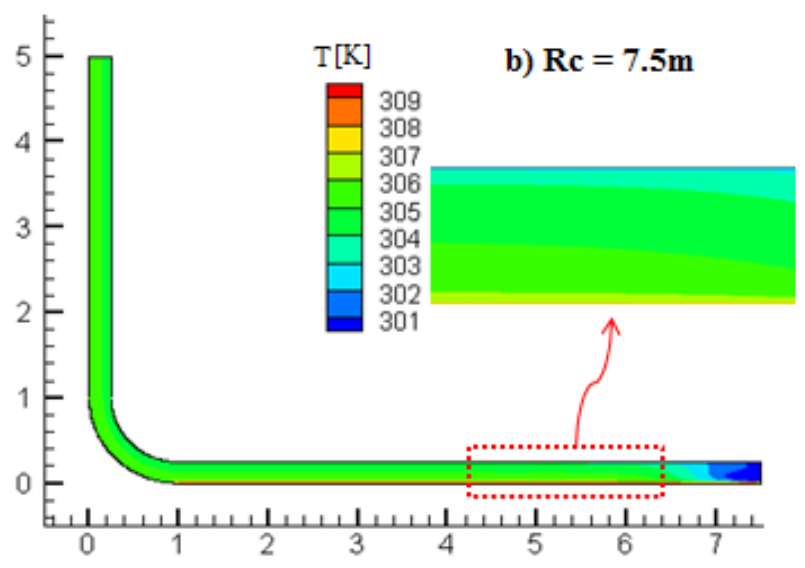

(b)

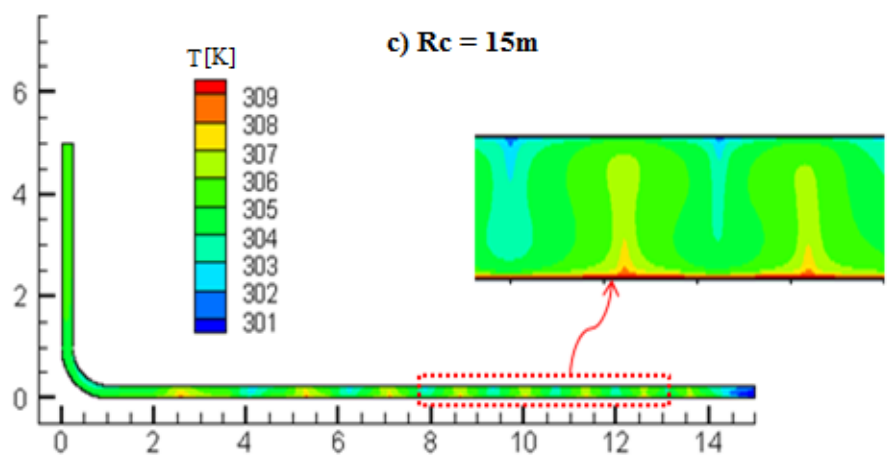

(c)

Fig. 13. (a)-(c) Isothermal contours evolution in the solar chimney for different collector radius

The air temperature evolution in a cross section of the collector $(r=0.25 \mathrm{~m})$ is illustrated in Figure 14. The results indicate that temperature first increases within the collector radius. Then, a minim decrease is noticed. 


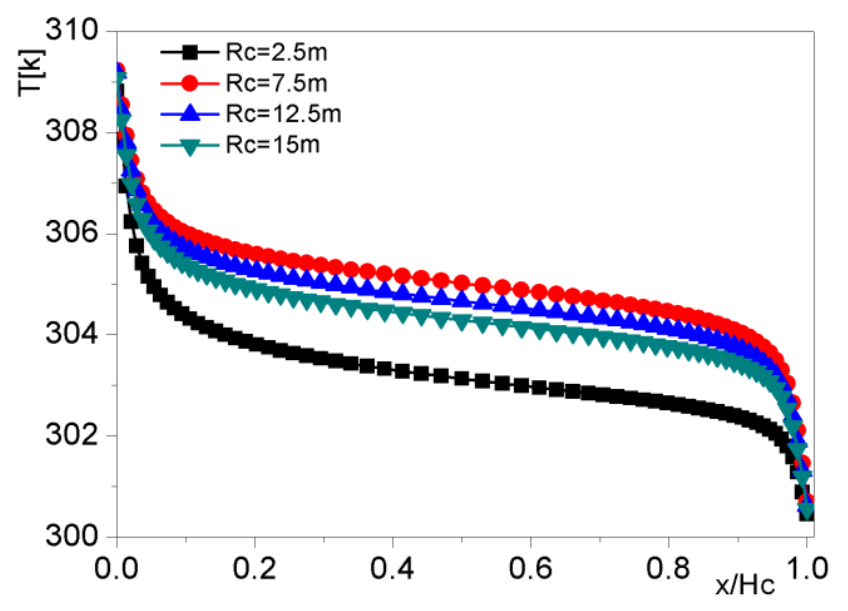

Fig. 14. Variation of temperature in a cross section of the collector $(r=0.25 \mathrm{~m})$, for different collector radius

\subsubsection{Collector radius effect on the mass flow rate}

Figure 15 shows the mass flow rate evolution versus the collector radius for a fixed collector height $(\mathrm{Hc}=0.25 \mathrm{~m})$. The mass flow rate increases until a maximum value, and then remains almost unchanged. Correlation of the mass flow rate as a function of the collector radius is given by:

$Q=-2.57 * 10^{-5}\left(\mathrm{Rc}^{4}\right)+1.03 * 10^{-3}\left(\mathrm{Rc}^{3}\right)-1.46 * 10^{-2}\left(\mathrm{Rc}^{2}\right)+8.85 * 10^{-2}(\mathrm{Rc})+0.0455$

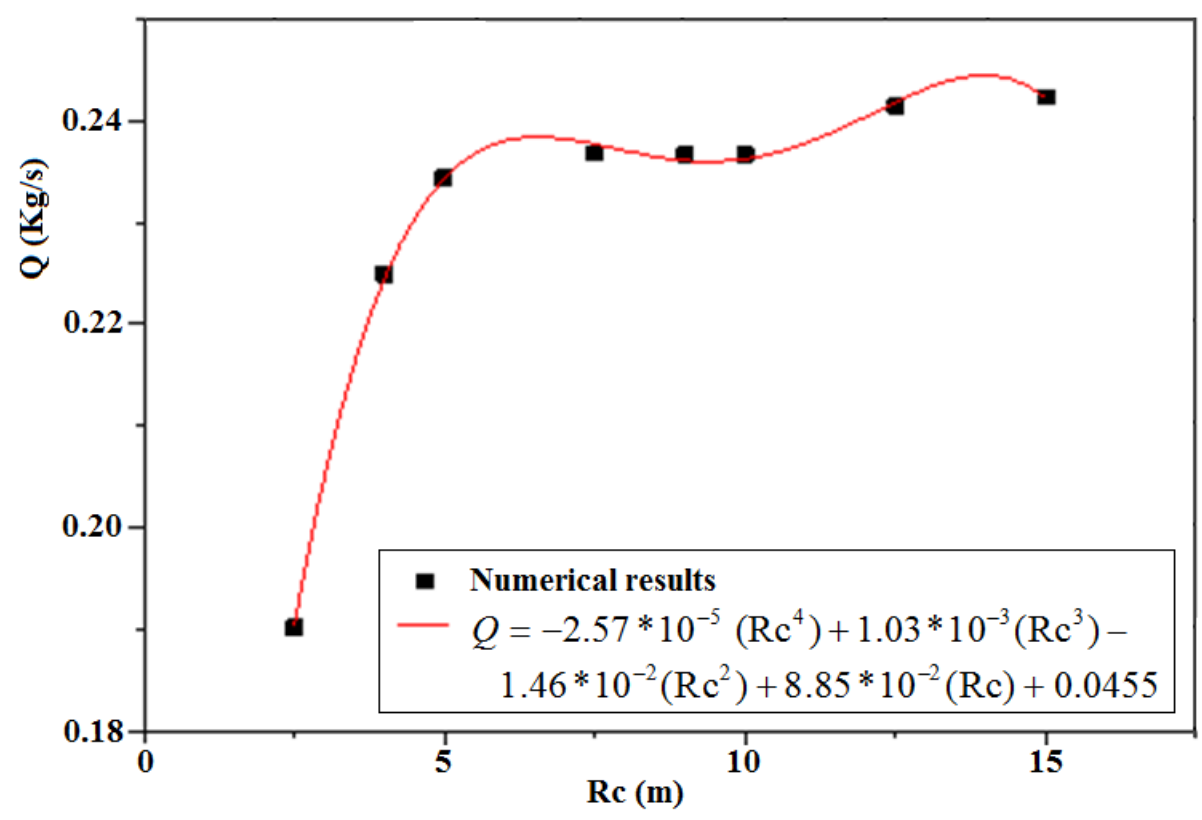

Fig. 15. Mass flow rate evolution versus the collector radius $(\mathrm{Hc}=0.25 \mathrm{~m})$

\section{Conclusion}

The collector geometrical parameters effect has been studied numerically. The finite volume method has been used to solve the governing equations of the flow. The model is validated using experimental results found in the literature. We note that both the collector height and radius affect intensively the flow behavior and the SCPP performance. The mass flow rate is enhanced by about 
$27 \%$, for $\mathrm{Rc}=12.5 \mathrm{~m}$ and $\mathrm{Hc}=0.25 \mathrm{~m}$. When varying collector height, the mass flow rate, first, increases; then, it deceases after reaching a maximum value. Thus, for a fixed value of collector radius, there is a corresponding optimum value for collector height. Concerning collector radius effect, the mass flow rate increases until a maximum value and then stabilizes. Accordingly, increasing collector radius beyond a certain value for a given collector height is not effective in improving the SCPP performance especially since it involves an additional investment cost.

\section{References}

[1] Haaf, W., K. Friedrich, G. Mayr, and Jorg Schlaich. "Solar chimneys part I: principle and construction of the pilot plant in Manzanares." International Journal of Solar Energy 2, no. 1 (1983): 3-20.

https://doi.org/10.1080/01425918308909911

[2] dos Santos Bernardes, Marco Aurelio, Ramon Molina Valle, and Márcio Fonte-Boa Cortez. "Numerical analysis of natural laminar convection in a radial solar heater." International journal of thermal sciences 38, no. 1 (1999): 4250 .

https://doi.org/10.1016/S0035-3159(99)80015-4

[3] Von Backström, T. W., and A. J. Gannon. "Solar chimney turbine characteristics." Solar energy 76, no. 1-3 (2004): 235-241.

https://doi.org/10.1016/i.solener.2003.08.009

[4] Maia, Cristiana B., André G. Ferreira, Ramón M. Valle, and Márcio FB Cortez. "Theoretical evaluation of the influence of geometric parameters and materials on the behavior of the airflow in a solar chimney." Computers \& Fluids 38, no. 3 (2009): 625-636.

https://doi.org/10.1016/i.compfluid.2008.06.005

[5] Chergui, Toufik, Salah Larbi, and Amor Bouhdjar. "Thermo-hydrodynamic aspect analysis of flows in solar chimney power plants-A case study." Renewable and Sustainable Energy Reviews 14, no. 5 (2010): 1410-1418.

https://doi.org/10.1016/i.rser.2010.01.017

[6] Larbi, Salah, Amor Bouhdjar, and Toufik Chergui. "Performance analysis of a solar chimney power plant in the southwestern region of Algeria." Renewable and Sustainable energy reviews 14, no. 1 (2010): 470-477. https://doi.org/10.1016/i.rser.2009.07.031

[7] Sangi, Roozbeh, Majid Amidpour, and Behzad Hosseinizadeh. "Modeling and numerical simulation of solar chimney power plants." Solar energy 85, no. 5 (2011): 829-838.

https://doi.org/10.1016/i.solener.2011.01.011

[8] Lebbi, M., T. Chergui, H. Boualit, and I. Boutina. "Influence of geometric parameters on the hydrodynamics control of solar chimney." International journal of hydrogen energy 39, no. 27 (2014): 15246-15255. https://doi.org/10.1016/j.ijhydene.2014.04.215

[9] Lebbi, M., H. Boualit, T. Chergui, L. Boutina, A. Bouabdallah, and H. Oualli. "Tower outlet/inlet radii ratio effects on the turbulent flow control in a solar chimney." In IREC2015 The Sixth International Renewable Energy Congress, pp. 1-6. IEEE, 2015.

https://doi.org/10.1109/IREC.2015.7110859

[10] Sudprasert, Sudaporn, Chatchawin Chinsorranant, and Phadungsak Rattanadecho. "Numerical study of vertical solar chimneys with moist air in a hot and humid climate." International Journal of Heat and Mass Transfer 102 (2016): 645-656. https://doi.org/10.1016/j.ijheatmasstransfer.2016.06.054

[11] Bayareh, Morteza. "Numerical simulation of a solar chimney power plant in the southern region of Iran." Energy Equipment and Systems 5, no. 4 (2017): 431-437.

[12] Zhou, Xinping, Jiakuan Yang, Bo Xiao, Guoxiang Hou, and Fang Xing. "Analysis of chimney height for solar chimney power plant." Applied Thermal Engineering 29, no. 1 (2009): 178-185. https://doi.org/10.1016/j.applthermaleng.2008.02.014

[13] Hamdan, Mohammad O. "Analysis of a solar chimney power plant in the Arabian Gulf region." Renewable Energy 36, no. 10 (2011): 2593-2598. https://doi.org/10.1016/j.renene.2010.05.002

[14] Lee, Duen-Sheng, Tzu-Chen Hung, Jaw-Ren Lin, and Jun Zhao. "Experimental investigations on solar chimney for optimal heat collection to be utilized in organic Rankine cycle." Applied Energy 154 (2015): 651-662. https://doi.org/10.1016/i.apenergy.2015.05.079

[15] Bouabidi, Abdallah, Haythem Nasraoui, Ahmed Ayadi, Zied Driss, and Mohamed Salah Abid. "Numerical and experimental study of the solar chimney with divergent collector." Heat Transfer Research 50, no. 9 (2019). 
https://doi.org/10.1615/HeatTransRes.2018024769

[16] Kinan, A., and NA Che Sidik. "Experimental studies on small scale of solar updraft power plant." Journal of Advanced Research Design 22, no. 1 (2016): 1-12.

http://www.akademiabaru.com/doc/ARDV22 N1 P1 12.pdf

[17] Nasraoui, Haythem, Zied Driss, and Hedi Kchaou. "Novel collector design for enhancing the performance of solar chimney power plant." Renewable Energy 145 (2020): 1658-1671. https://doi.org/10.1016/i.renene.2019.07.062

[18] Elwekeel, Fifi NM, Antar MM Abdala, and Muhammad Mustafizur Rahman. "Effects of novel collector roof on solar chimney power plant performance." Journal of Solar Energy Engineering 141, no. 3 (2019). https://doi.org/10.1115/1.4041403

[19] Ayadi, Ahmed, Zied Driss, Abdallah Bouabidi, and Mohamed Salah Abid. "Experimental and numerical study of the impact of the collector roof inclination on the performance of a solar chimney power plant." Energy and Buildings 139 (2017): 263-276.

https://doi.org/10.1016/j.enbuild.2017.01.047

[20] Li, Jing-yin, Peng-hua Guo, and Yuan Wang. "Effects of collector radius and chimney height on power output of a solar chimney power plant with turbines." Renewable Energy 47 (2012): 21-28.

https://doi.org/10.1016/i.renene.2012.03.018

[21] Ayadi, Ahmed, Abdallah Bouabidi, Zied Driss, and Mohamed Salah Abid. "Experimental and numerical analysis of the collector roof height effect on the solar chimney performance." Renewable energy 115 (2018): 649-662. https://doi.org/10.1016/j.renene.2017.08.099

[22] Kebabsa, Hakim, Mohand Said Lounici, Mohamed Lebbi, and Ahmed Daimallah. "Thermo-hydrodynamic behavior of an innovative solar chimney." Renewable Energy 145 (2020): 2074-2090.

https://doi.org/10.1016/i.renene.2019.07.121 